\title{
EFEK PENAMBAHAN MINYAK ZAITUN PADA PEREKAT ALAMI BERBAHAN DASAR TEPUNG TAPIOKA
}

\section{Bima Prasetya Pancasakti, Vincent}

Universitas Gadjah Mada (UGM) Yogyakarta, Indonesia

Email: bimaprasetya@mail.ugm.ac.id, vincent2018@mail.ugm.ac.id

\begin{abstract}
Abstrak
Pengembangan kualitas perekat alami untuk industri kayu merupakan hal yang menarik untuk dikaji. Penelitian ini bertujuan untuk meningkatkan kualitas perekat alami berbahan dasar tepung tapioka menggunakan minyak zaitun. Kandungan gugus fenol yang banyak membuat minyak zaitun berpeluang digunakan sebagai bahan aditif untuk perekat. Pembuatan perekat dilakukan dengan metode hidrolisis, oksidasi, polimerisasi dan penambahan minyak zaitun. Pengujian berupa viskositas, kandungan padatan, kuat geser kering dan basah dilakukan untuk mengetahui kualitas perekat. Hasil percobaan menunjukkan bahwa viskositas PA25\% mengalami peningkatan dibandingkan dengan viskositas PA0\%. Seiring dengan penambahan minyak zaitun, kandungan padatan di dalam perekat dan kuat geser kering mengalami mengalami penurunan. Reaksi polimerisasi antara monomer MMA yang digunakan dengan tepung tapioka serta penambahan minyak zaitun tidak memberikan kekuatan daya rekat yang memuaskan.
\end{abstract}

Kata Kunci: perekat alami, tepung tapioka, minyak zaitun, polimerisasi.

\begin{abstract}
The development of the quality of bioadhesive is an interesting subject to be studied. This study aims to improve the quality of starch-based bioadhesive using olive oil. The high content of phenolic functional groups makes an opportunity for olive oil to be used as an additive for adhesive. The bioadhesive was made by hydrolysis, oxidation, polymerization, and olive oil addition. The viscosity measurement, solid content measurement, dry and wet shear strength analysis were carried out to determine the quality of bioadhesive. The result showed that the viscosity of PA25\% has increased compared to the viscosity of PAO\%. The solid content and dry shear strength of the adhesive decreased along with the increase of olive oil. Polymerization reaction between MMA monomer and cassava starch as well as olive oil addition did not provide satisfactory adhesion strength.
\end{abstract}

Keywords: bioadhesive, cassava starch, olive oil, polymerization.

\begin{tabular}{ll}
\hline How to cite: & Prasetya Pancasakti Bima, Vincent. (2021) Efek Penambahan Minyak Zaitun Pada Perekat Alami \\
& Berbahan Dasar Tepung Tapioka Syntax Idea, 3(7). https:// doi.org/10.36418/syntax-idea.v3i7.1352 \\
E-ISSN: & 2684-883X \\
Published by: & Ridwan Institute
\end{tabular}




\section{Pendahuluan}

Penggunaan perekat kayu terus meningkat seiring dengan perkembangan industri kayu (Kaboorani \& Riedl, 2011). Perekat kayu memiliki peranan penting dalam industri furnitur, konstruksi, dan bangunan (Xu, Wen, \& Wang, 2016). Jenis perekat kayu yang paling banyak digunakan hingga saat ini merupakan perekat sintetis yang berasal dari minyak bumi seperti fenol-formaldehid dan urea-formaldehid. Perekat sintetis tersebut mengandung berbagai zat organik volatil yang bersifat karsinogenik sehingga dapat mengancam kesehatan manusia (Jang, Huang, \& Li, 2011). Salah satu alternatif untuk mengurangi penggunaan perekat sintetis adalah dengan membuat perekat alami. Beberapa tahun terakhir, penggunaan tepung tapioka sebagai bahan baku perekat alami cukup digemari (Yu, Fang, Cao, \& Liu, 2016). Kelebihan yang dimiliki tepung tapioka adalah harga yang terjangkau, jumlahnya melimpah, tidak beracun, serta dapat terurai dan diperbarui.

Berbagai macam studi mengenai pembuatan perekat kayu alami berbahan dasar tepung telah dilakukan. Metode yang digunakan seperti hidrolisis asam, graft polymerization, oksidasi, gelatinisasi dan modifikasi lainnya sudah dikembangkan (Wang, Li, Gu, Hong, \& Cheng, 2012). Akan tetapi, daya rekat yang dihasilkan cenderung lebih lemah dibandingkan dengan perekat sintetis. Adanya retrogradasi zat pati berpotensi menurunkan performa perekat berbahan dasar tepung (Li et al., 2014). Selain itu, perekat berbahan dasar tepung juga tidak tahan lama. Berbagai solusi yang ditawarkan untuk meningkatkan kualitas perekat alami yaitu dengan penambahan zat aditif berupa SDS (Li et al., 2014), katalis asam (Gadhave, Mahanwar, Gadekar, \& Kasbe, 2019) serta minyak nabati (Xing, Li, Yu, Chen, \& Chang, 2018).

Penggunaan minyak nabati sebagai zat aditif seperti minyak canola (Kong, Liu, \& Curtis, 2011), minyak jarak (Gama, Ferreira, \& Barros-Timmons, 2019) minyak biji rami (Addis, Koh, \& Gordon, 2020) dan minyak hasil pirolisis dari tumbuhan (Özbay \& Ayrilmis, 2015) menunjukan peningkatan kualitas sifat dari perekat. Peningkatan kualitas tersebut dikarenakan adanya reaksi antara gugus di dalam minyak nabati dengan tepung tapioka (Issola, Kamlo, Yona, \& Ndikontar, 2018). Minyak nabati dengan harga yang murah dan mudah diperbarui memiliki banyak jenis gugus fungsi seperti alkohol, aldehid, karboksilat, ester, eter, furan, keton dan fenol berpeluang untuk dimanfaatkan sebagai pengganti bahan fosil dalam pembuatan perekat alami (Bridgwater, 2012).

Salah satu minyak nabati yang mudah untuk diperoleh di Indonesia adalah minyak zaitun. Minyak zaitun merupakan minyak nabati yang diperoleh dari buah zaitun yang melalui pemrosesan secara mekanis (Peri, 2014). Komponen utama minyak zaitun adalah triasilgliserol. Adanya gugus fenol pada minyak zaitun dapat digunakan sebagai antibakteri dan anti jamur (Xing et al., 2018).

Tujuan dari penelitian ini adalah untuk meningkatkan kualitas perekat tepung tapioka termodifikasi dengan menambahkan minyak zaitun. Tepung tapioka termodifikasi merupakan tepung yang telah mengalami proses hidrolisis, oksidasi dan 
polimerisasi dengan monomer. Pengujian berupa kuat tarik, viskositas dan kandungan padatan dilakukan untuk mengetahui efek dari penambahan minyak zaitun ke dalam perekat tepung tapioka termodifikasi.

\section{Metode Penelitian}

Bahan yang digunakan dalam penelitian ini adalah tepung tapioka (PT. Budi Acid Jaya Tbk); Minyak zaitun (CV. Gudang Kimia); Amonium Persulfat $\left(\left(\mathrm{NH}_{4}\right)_{2} \mathrm{~S}_{2} \mathrm{O}_{8}\right)$ (LPPT UGM, Yogyakarta); Methyl Methacrylate (MMA) (FRP Jakarta); Polyvinyl alcohol (PVA) (CV. Gudang Kimia); Sodium dodecyl sulfate (SDS) (CV. Gudang Kimia); Asam klorida ( $\mathrm{HCl}$ ) 37\% (Laboratorium Teknik Reaksi Kimia, Fakultas Teknik, Universitas Gadjah Mada); Papan kayu (UD. Makmur Jaya).

Sebanyak $100 \mathrm{~g}$ tepung tapioka dan $150 \mathrm{~mL} \mathrm{HCl}(0.5 \mathrm{~mol} / \mathrm{L})$ dimasukkan ke dalam labu leher tiga berpengaduk yang diletakkan pada pemanas mantel dengan suhu $60{ }^{\circ} \mathrm{C}$ selama 10 menit. Selanjutnya, sebanyak $18 \mathrm{~g}\left(\mathrm{NH}_{4}\right)_{2} \mathrm{~S}_{2} \mathrm{O}_{8}(10 \% \mathrm{wt})$ ditambahkan dan diaduk dengan kecepatan putaran 500 rpm selama 50 menit. Sebanyak 120 g PVA (10\% wt) dan 2,28 g SDS ditambahkan. Kemudian sebanyak $50 \mathrm{~mL}$ monomer MMA ditambahkan secara berkala dalam kurun waktu 3 jam. Setelah 1,5 jam, sebanyak 4,5 g $\left(\mathrm{NH}_{4}\right)_{2} \mathrm{~S}_{2} \mathrm{O}_{8}$ ditambahkan dan reaksi dijalankan selama 2,5 jam. Kemudian sebanyak 15 g minyak zaitun ditambahkan secara berkala selama 30 menit. Kecepatan penambahan dipengaruhi oleh viskositas dari sistem saat bereaksi. Setelah 35 menit, perekat alami (PA) yang diperoleh didinginkan pada suhu kamar.

Pengujian viskositas dilakukan menggunakan viskometer Brookfield yang mengacu pada ASTM-D1084. Guard leg dipasang pada viskometer. Jenis spindle yang digunakan dipilih berdasarkan kebutuhan. Spindle dipasang pada poros (lower shaft). Spindle kemudian direndam ke dalam sampel hingga batas lekukan pada batang spindle. Spindle diusahakan untuk tidak mengenai wadah dari sampel. Tombol SPDL ditekan dan nomor spindle dimasukkan sesuai dengan lampiran. Setelah dua digit nomor, tombol \%, CPS atau SS ditekan secara bersamaan. Pengujian sampel dilakukan dengan tombol motor $O n$ ditekan dan pembacaan dibiarkan stabil dimana kesalahan pada viskometer menunjukkan angka berkisar $20 \%$.

Pengujian kandungan padatan dilakukan berdasarkan atas standar ASTM-D2369. Sebanyak $1 \mathrm{~g}$ sampel yang diletakan dalam cawan petri dimasukkan ke oven pada suhu $110 \pm 2,5^{\circ} \mathrm{C}$ selama 60 menit. Setelah proses pengovenan, sampel dimasukan ke dalam eksikator selama 10 menit. Sampel kemudian ditimbang dengan neraca analitis digital dan hasil penimbangan dicatat. Percobaan diulangi sehingga diperoleh 3 data untuk masing-masing sampel.

Pengujian kuat geser kering didasarkan atas standar ASTM-D906. Perekat dioleskan pada area seluas $30 \times 25 \mathrm{~mm}$ dengan pengaplikasian perekat $0,2 \mathrm{mg} / \mathrm{mm}^{2}$. Sampel diletakkan dalam suhu ruangan dan diberikan tekanan sebesar 3,27 $\times 10^{-2}$ $\mathrm{N} / \mathrm{mm}^{2}$ pada area yang direkatkan selama 24 jam. Setelah 24 jam, sampel diletakkan dalam ruangan yang kering pada suhu $25{ }^{\circ} \mathrm{C}$ dengan $\mathrm{RH} 50 \%$ selama 7 hari. Kuat geser sampel kemudian diuji menggunakan Universal Testing Machine dan ditarik secara 
konstan $10 \mathrm{~mm} / \mathrm{min}$. Pengujian diulangi sehingga diperoleh 5 data untuk masing-masing sampel.

Pengujian kuat geser basah didasarkan atas standar ASTM-D1183. Kayu yang telah direkatkan diberikan tekanan sebesar $3,27 \times 10^{-2} \mathrm{~N} / \mathrm{mm}^{2}$ pada area yang direkatkan selama 24 jam direndam ke dalam air pada suhu ruang selama 24 jam dan kemudian dikeringkan pada suhu ruang selama 24 jam. Setelah itu sampel diletakkan pada suhu ruang selama 7 hari yang kemudian kuat geser sampel diuji menggunakan menggunakan Universal Testing Machine dan ditarik secara konstan $10 \mathrm{~mm} / \mathrm{min}$. Pengujian dilakukan berulang hingga diperoleh 5 sampel.

\section{Hasil dan Pembahasan}

Pada penelitian ini dilakukan variasi penambahan minyak zaitun ke dalam perekat tepung tapioka. Penambahan minyak zaitun tersebut dilakukan sebanyak 0\%, 10\%, $15 \%, 20 \%$ dan $25 \%$ dari berat tepung tapioka. Sampel yang telah dibuat kemudian disebut sebagai PA0\%, PA10\%, PA15\%, PA20\% dan PA25\%. Sampel PA0\% merupakan variabel kontrol yang digunakan sebagai pembanding terhadap sampel lainnya. Pengujian berupa viskositas, kandungan padatan, kuat geser kering dan basah dan dilakukan untuk mengetahui kualitas dari perekat yang dihasilkan.

Terdapat beberapa mekanisme reaksi di dalam pembuatan perekat ini. Mekanisme pertama adalah reaksi hidrolisis tepung tapioka. Hidrolisis tepung tapioka dilakukan dengan menggunakan bantuan asam klorida $(\mathrm{HCl})$. Proses ini berlangsung pada suhu 60 ${ }^{\circ} \mathrm{C}$ selama 10 menit. Tujuan utama dari proses ini adalah untuk memecah ikatan glikosidik di dalam tepung tapioka. Sampel yang telah mengalami hidrolisis akan dioksidasi dengan menggunakan amonium persulfat $\left(\left(\mathrm{NH}_{4}\right)_{2} \mathrm{~S}_{2} \mathrm{O}_{8}\right)$ selama 50 menit. Proses oksidasi bertujuan untuk mengubah gugus hidroksil $(-\mathrm{OH})$ di dalam tepung tapioka menjadi gugus aldehid (-CHO) atau karboksilat (-COOH). Polivinil alkohol (PVA) dan sodium dodecyl sulfate (SDS) yang ditambahkan setelah proses oksidasi berfungsi sebagai bahan pengisi untuk meningkatkan kualitas rekat dari sampel, diikuti dengan penambahan monomer metil metakrilat (MMA). Penambahan MMA dilakukan secara berkala agar reaksi polimerisasi dapat berjalan dengan baik sehingga diperoleh konversi yang maksimum. Dalam hal ini diharapkan terjadinya reaksi polimerisasi antara gugus akrilat dalam MMA dengan gugus aldehid atau karboksilat dalam tepung yang sudah teroksidasi. Proses kemudian dilanjutkan 1,5 jam sebelum penambahan $\left(\mathrm{NH}_{4}\right)_{2} \mathrm{~S}_{2} \mathrm{O}_{8}$ yang bertujuan agar proses polimerisasi berjalan sempurna. Proses oksidasi kemudian dilanjutkan hingga 2,5 jam. Penambahan minyak dilakukan secara berkala selama 30 menit. Penambahan minyak zaitun bertujuan sebagai agen penghubung ikatan antara tepung tapioka dengan PVA maupun MMA. Ikatan yang terbentuk adalah hasil reaksi esterifikasi antara gugus karboksilat pada minyak zaitun dengan gugus hidroksil pada tepung yang belum mengalami oksidasi. 
Tabel 1

Viskositas Perekat Pada Berbagai Sampel

\begin{tabular}{cccc}
\hline \multirow{2}{*}{ Sampel } & \multirow{2}{*}{ Kandungan Minyak, $\%$} & \multicolumn{2}{c}{ Viskositas, cP } \\
\cline { 3 - 4 } & & $60 \mathrm{rpm}$ & $100 \mathrm{rpm}$ \\
\hline PA0\% & $0 \%$ & 162,5 & 113,0 \\
\hline PA10\% & $10 \%$ & 76,9 & 52,7 \\
\hline PA15\% & $15 \%$ & 220,6 & 163,1 \\
\hline PA20\% & $20 \%$ & 94,4 & 67,5 \\
\hline PA25\% & $25 \%$ & 172,8 & 115,3 \\
\hline
\end{tabular}

Pengujian viskositas dilakukan dengan mengikuti standar ASTM-D1084. Dilakukan pengujian pada putaran $60 \mathrm{rpm}$ dan $100 \mathrm{rpm}$ bertujuan untuk mengetahui kekentalan dari perekat dalam putaran spindle yang ditentukan. Hal ini dilakukan karena perekat yang dihasilkan merupakan jenis fluida non-newtonian thixotropic. Hasil pengujian viskositas pada masing-masing sampel terdapat pada Tabel 1. Sampel perekat mengalami penurunan nilai viskositas ketika ditambahkan dengan minyak zaitun. Penambahan ini menyebabkan jumlah air yang dihasilkan semakin meningkat sehingga kekentalan dari perekat menjadi berkurang. Namun, penurunan viskositas tersebut tidaklah linier. Terdapat sampel perekat yang mengalami peningkatan viskositas seperti PA15\% dan PA25\%. Peningkatan viskositas pada kedua sampel ini dikarenakan naiknya berat molekul rata-rata yang disebabkan oleh reaksi antara minyak zaitun dan pati dalam tepung tapioka. Penambahan minyak zaitun juga dapat menjaga kualitas dari perekat untuk tidak mudah berjamur dan mengalami pengerasan.

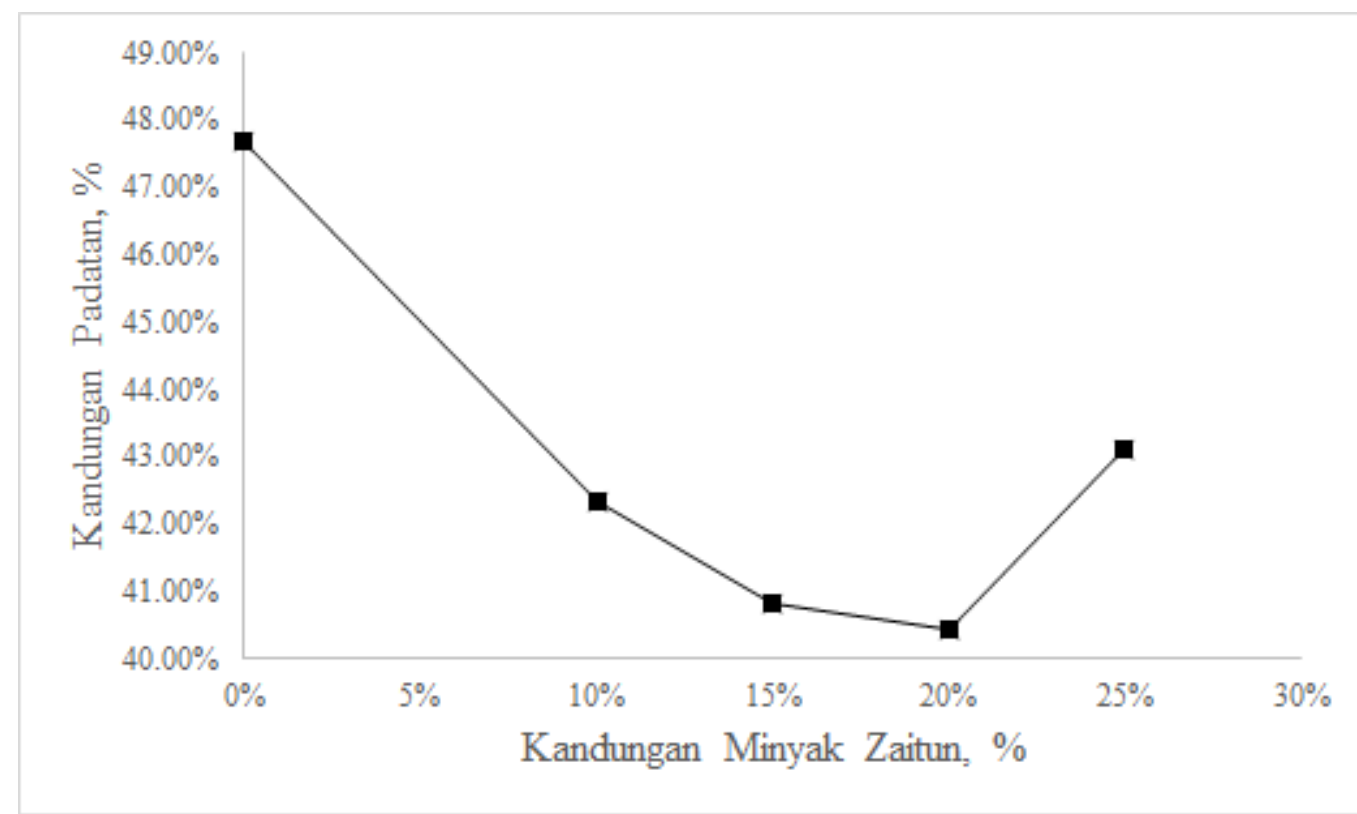

\section{Gambar 1}

Hubungan Antara Kandungan Minyak Zaitun Pada Perekat Alami dengan Kandungan Jumlah Padatan 
Pengujian kandungan padatan dilakukan berdasarkan ketentuan standar ASTMD2369. Pengujian ini bertujuan untuk mengetahui tingkat volatilitas perekat. Semakin rendah volatilitas suatu perekat, maka semakin sedikit zat volatil berbahaya yang terhirup oleh manusia. Kandungan padatan perekat pada berbagai jenis sampel ditunjukkan pada Gambar 1. Kandungan padatan tertinggi adalah 47,69\% pada sampel PA0\% dan kandungan padatan terendah sebesar 40,42\% pada sampel PA20\%. Berdasarkan Gambar 1. semakin banyak minyak zaitun yang ditambahkan ke dalam perekat, maka kandungan padatan semakin menurun. Penurunan kandungan padatan tersebut dikarenakan jumlah air yang meningkat seiring dengan penambahan minyak zaitun. Jumlah air di dalam perekat akan mempengaruhi perhitungan massa perekat sebelum dioven dan setelah dioven.

Pada sampel PA25\%, terjadi peningkatan kandungan padatan sebesar 43,10\%. Peningkatan kandungan padatan ini menunjukkan bahwa reaksi antara minyak zaitun dengan pati dalam tepung tapioka telah terjadi dengan sempurna. Reaksi yang terjadi menyebabkan jumlah berat molekul di dalam sampel bertambah sehingga total kandungan padatan di dalam sampel juga bertambah. Gugus fenol di dalam minyak zaitun akan bereaksi dengan gugus aldehid atau karboksilat di dalam tepung tapioka yang telah dioksidasi. Reaksi esterifikasi juga terjadi antara asam di dalam minyak zaitun dengan gugus hidroksil di dalam tepung tapioka yang belum teroksidasi.

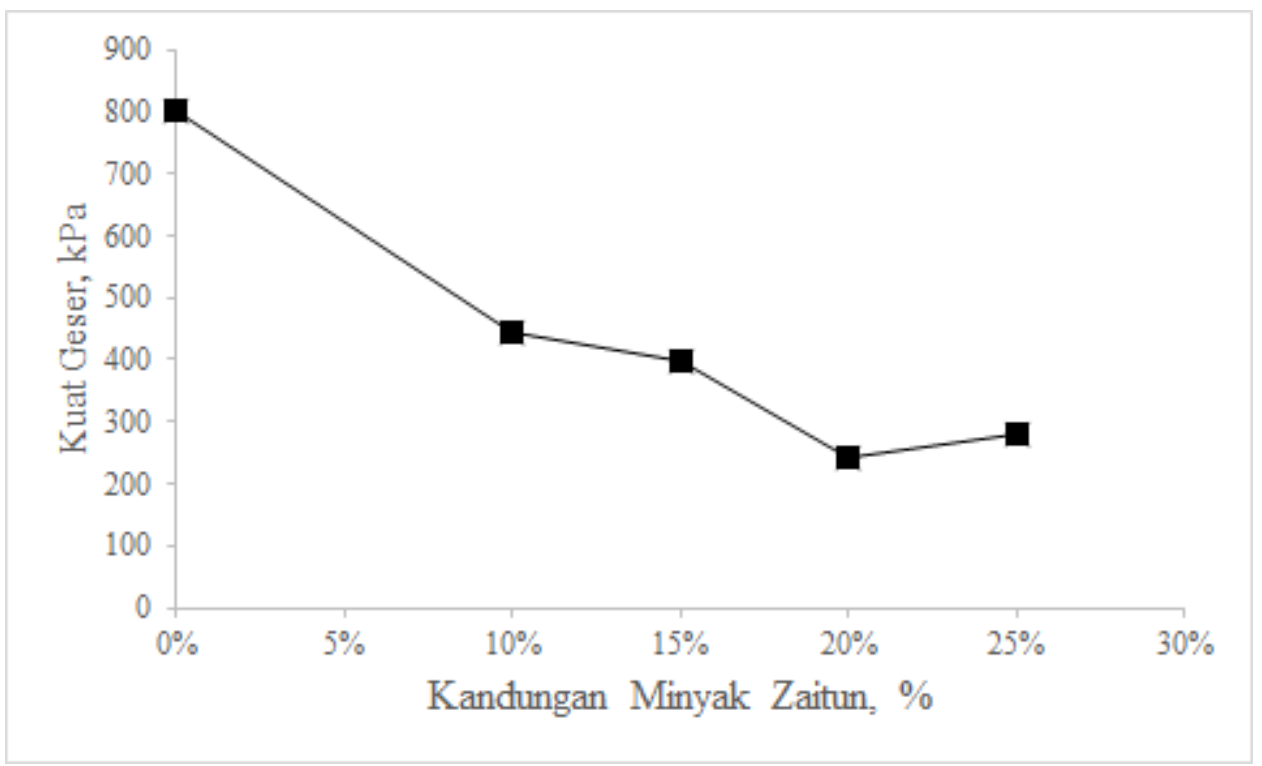

Gambar 2

\section{Hubungan Antara Kandungan Minyak Zaitun Pada Perekat Alami dengan Kuat Geser Kering}

Pengujian kuat geser kering dilakukan berdasarkan standar ASTM-D906 sedangkan kuat geser basah berdasarkan standar ASTM-D1183. Sampel perekat yang 
telah dibuat kemudian diaplikasikan ke kayu jati sebanyak 5 sampel. Kelima sampel tersebut diberikan perlakuan yang sama sehingga diperoleh hasil yang akurat. Pengujian kuat geser kering dari perekat ditunjukkan pada Gambar 2. Kuat geser tertinggi adalah $801,31 \mathrm{kPa}$ pada sampel PA0\% dan kuat geser terendah sebesar 241,51 kPa pada sampel PA20\%. Dari hasil pengujian, dapat diketahui bahwa perekat alami ini tidak tahan air. Kelima sampel kayu yang diuji mengalami kerapuhan daya rekat setelah perendaman sehingga mudah lepas. Resisten terhadap air yang lemah disebabkan penggunaan minyak zaitun sebagai bahan aditif sehingga dapat memperlemah daya rekat dari perekat ketika terkena air. Hal tersebut dikarenakan adanya sifat hidrofobik pada minyak zaitun yang tercampur di dalam perekat. Sifat hidrofobik ini menyebabkan kekuatan rekat antar kayu menjadi rapuh apabila terkena air. Gaya dorong antara minyak dan air saat proses perekatan menyebabkan kayu menjadi rentan untuk lepas.

Penambahan jumlah minyak zaitun ke dalam sampel perekat menyebabkan kuat geser kering dari perekat semakin menurun. Hal ini karena adanya kandungan air dalam minyak zaitun yang menyebabkan kekuatan perekat semakin berkurang. Pada sampel PA25\%, kuat geser kering mulai mengalami peningkatan menjadi 281,47 kPa. Peningkatan tersebut disebabkan reaksi antara minyak zaitun dengan tepung tapioka telah berjalan sempurna. Reaksi yang sempurna menghasilkan daya rekat yang lebih kuat dibandingkan dengan sampel sebelumnya. Reaksi yang terjadi pada sampel ini adalah reaksi antara aldehid dengan tepung tapioka yang membentuk ikatan penghubung. Ikatan kovalen yang terbentuk juga disebabkan reaksi esterifikasi antara asam pada minyak zaitun dengan gugus hidroksil pada tepung tapioka.

Penggunaan monomer di dalam pembuatan perekat ini bertujuan untuk memperkuat daya rekat dari perekat. Penambahan ini bertujuan agar terbentuknya graft copolymer starch yang dapat meningkatkan kualitas rekat dari perekat. Penggunaan jenis monomer sebagai bahan aditif perlu diperhatikan. Dalam penelitian ini digunakan monomer MMA yang diharapkan dapat memperkuat sifat adhesi perekat. Namun penambahan monomer ini ternyata dapat memperlemah daya rekat dari perekat. Pelemahan daya rekat tersebut dapat disebabkan oleh terbentuknya butiran-butiran polimer yang menyebabkan perekat menjadi tidak homogen dalam satu fase. Sehingga dengan adanya penambahan polimer akan menyebabkan terjadi retrogradasi ulang antar tepung tapioka dengan monomer MMA. Akibatnya permukaan lem menjadi tidak merata ketika diaplikasikan pada kayu yang direkatkan.

\section{Kesimpulan}

Hasil penelitian menunjukkan bahwa nilai kandungan padatan tertinggi dicapai ketika penambahan minyak zaitun sebanyak $25 \%$ dari massa tepung tapioka. Semakin banyak minyak zaitun yang ditambahkan maka daya rekat semakin berkurang. Reaksi polimerisasi antara tepung tapioka dengan MMA tidak memberikan hasil yang memuaskan terhadap kualitas perekat. Pemilihan jenis monomer yang sesuai perlu dipertimbangkan agar perekat yang terbentuk memiliki daya rekat yang kuat. 


\section{BIBLIOGRAFI}

Addis, Clark C., Koh, Rachel S., \& Gordon, Melissa B. (2020). Preparation and characterization of a bio-based polymeric wood adhesive derived from linseed oil. International Journal of Adhesion and Adhesives, 102, 102655.Google Scholar

Bridgwater, Anthony V. (2012). Review of fast pyrolysis of biomass and product upgrading. Biomass and Bioenergy, 38, 68-94. Google Scholar

Gadhave, Ravindra V, Mahanwar, Prakash A., Gadekar, Pradeep T., \& Kasbe, Pratik S. (2019). A study on the effect of starch-polyvinyl alcohol blends by addition of citric acid and boric acid for enhancement in performance properties of polyvinyl acetate-based wood adhesive. Journal of the Indian Academy of Wood Science, 112. Google Scholar

Gama, Nuno, Ferreira, Artur, \& Barros-Timmons, Ana. (2019). Cure and performance of castor oil polyurethane adhesive. International Journal of Adhesion and Adhesives, 95, 102413. Google Scholar

Issola, A. G., Kamlo, A. Ngueteu, Yona, A. M., \& Ndikontar, M. (2018). Chemical Modification of Cassava Starch by Transesterification Using Vegetable Oil/Aluminum Chloride. Journal of Renewable Materials, 6(6), 642-650. Google Scholar

Jang, Yonghwan, Huang, Jian, \& Li, Kaichang. (2011). A new formaldehyde-free wood adhesive from renewable materials. International Journal of Adhesion and Adhesives, 31(7), 754-759. Google Scholar

Kaboorani, Alireza, \& Riedl, Bernard. (2011). Effects of adding nano-clay on performance of polyvinyl acetate (PVA) as a wood adhesive. Composites Part A: Applied Science and Manufacturing, 42(8), 1031-1039. Google Scholar

Kong, Xiaohua, Liu, Guoguang, \& Curtis, Jonathan M. (2011). Characterization of canola oil based polyurethane wood adhesives. International Journal of Adhesion and Adhesives, 31(6), 559-564. Google Scholar

Li, Zhaofeng, Wang, Jian, Cheng, Li, Gu, Zhengbiao, Hong, Yan, \& Kowalczyk, Agnieszka. (2014). Improving the performance of starch-based wood adhesive by using sodium dodecyl sulfate. Carbohydrate Polymers, 99, 579-583. Google Scholar

Özbay, Günay, \& Ayrilmis, Nadir. (2015). Bonding performance of wood bonded with adhesive mixtures composed of phenol-formaldehyde and bio-oil. Industrial Crops and Products, 66, 68-72. Google Scholar

Peri, C. (2014). The Extra-Virgin Olive Oil Handbook. Chicester: John Wiley \& Sons.

Wang, Zhenjiong, Li, Zhaofeng, Gu, Zhengbiao, Hong, Yan, \& Cheng, Li. (2012). 
Bima Prasetya Pancasakti, Vincent

Preparation, characterization and properties of starch-based wood adhesive. Carbohydrate Polymers, 88(2), 699-706. Google Scholar

Xing, Jingchen, Li, Tingting, Yu, Yuxiang, Chen, Chao, \& Chang, Jianmin. (2018). Google Scholar

Development and characterization of a new bio-adhesive for wood using cassava starch and bio-oil. International Journal of Adhesion and Adhesives, 87, 91-97. Google Scholar

Xu, Qing, Wen, Jianping, \& Wang, Zhenjiong. (2016). Preparation and properties of cassava starch-based wood adhesives. BioResources, 11(3), 6756-6767. Google Scholar

Yu, Hongwei, Fang, Qun, Cao, Yuan, \& Liu, Zhikun. (2016). Effect of HCl on starch structure and properties of starch-based wood adhesives. BioResources, 11(1), 1721-1728. Google Scholar

\section{Copyright holder:}

Bima Prasetya Pancasakti, Vincent (2021)

\section{First publication right:}

Syntax Idea

This article is licensed under:

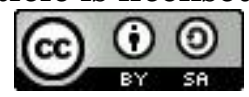

